\title{
Foreword
}

\section{Airat Bikchentaev ${ }^{1}$. Soroush Rafiee Rad ${ }^{2}$ • Ekaterina Turilova ${ }^{1}$}

Accepted: 12 January 2021 / Published online: 11 March 2020

(C) The Author(s), under exclusive licence to Springer Science+Business Media, LLC part of Springer Nature 2021

This issue contains papers of lectures and talks presented at the 14th biannual meeting of the International Quantum Structures Association (IQSA) in 2018 and the related satellite meeting at the International Quantum Physics and Logic conference (QPL) in 2017.

The 14th Biannual IQSA Conference was hosted by the Kazan Federal University, Kazan, Russian Federation, July 16-20, 2018 and the satellite meeting of 2017 was hosted at the Radboud University Nijmegen, The Netherlands, July 3-7, 2017. The presentations and talks at the two events covered a wide range of topics that are of interest in physical, mathematical and philosophical study of quantum structures. These include Quantum logic, Quantum probability, operator algebras, orthomodular lattices and effect algebras as well as topics on quantum computation and quantum linguistics amongst others. The two meetings also featured keynote speeches by internationally renowned scholars such as Guido Bacciagaluppi (Utrecht University), Hans Maassen (Radboud University Nijmegen), Oleg Smolyanov (Moscow State University), Grigorii Amosov (Steklov Mathematical Institute), Mirko Navara (Czech Technical University in Prague). We thank the President of the Kazan Federal University and the organisers of the QPL at the Radboud University Nijmegen for their support.

Scientifically, the meetings were a great success witnessed by the high quality of presentations and the ensuing discussions. The meetings allowed IQSA scholars from all around the world to share their research, develop new ideas and foster new collaborations. All contributions to the meetings have been subject to a high standard of peer review process and the quality of the papers collected in this special issue is a testimony to the quality of the research presented at the meetings.

Soroush Rafiee Rad

Soroush.RafieeRad@uni-bayreuth.de

Airat Bikchentaev

Airat.Bikchentaev@kpfu.ru

Ekaterina Turilova

Ekaterina.Turilova@kpfu.ru

1 Kazan University, Russian Federation, Kazan, Russia

2 Bayreuth University, Bayreuth, Germany 
We thank the editor-in-chief of the International Journal of Theoretical Physics for the preparation of this issue. Finally, we thank the IQSA members for their cooperative help and their work as referees and, last but not least, the student helpers at the conference, who also helped the participants during the meetings.

Publisher's Note Springer Nature remains neutral with regard to jurisdictional claims in published maps and institutional affiliations. 